\title{
Instability of delaminated composite cylindrical shells under combined axial compression and bending
}

DOI:

10.1016/j.compstruct.2007.01.021

\section{Document Version}

Accepted author manuscript

Link to publication record in Manchester Research Explorer

\section{Citation for published version (APA):}

Tafreshi, A. (2008). Instability of delaminated composite cylindrical shells under combined axial compression and bending. Composite Structures, 82(3), 422-433. https://doi.org/10.1016/j.compstruct.2007.01.021

\section{Published in:}

Composite Structures

\section{Citing this paper}

Please note that where the full-text provided on Manchester Research Explorer is the Author Accepted Manuscript or Proof version this may differ from the final Published version. If citing, it is advised that you check and use the publisher's definitive version.

\section{General rights}

Copyright and moral rights for the publications made accessible in the Research Explorer are retained by the authors and/or other copyright owners and it is a condition of accessing publications that users recognise and abide by the legal requirements associated with these rights.

\section{Takedown policy}

If you believe that this document breaches copyright please refer to the University of Manchester's Takedown Procedures [http://man.ac.uk/04Y6Bo] or contact uml.scholarlycommunications@manchester.ac.uk providing relevant details, so we can investigate your claim.

\section{OPEN ACCESS}


Tafreshi, A. Feb 2008 In : Composite Structures.82, 3, p. $422-43311$ p.

\title{
INSTABILITY OF DELAMINATED COMPOSITE CYLINDRICAL SHELLS UNDER COMBINED AXIAL COMPRESSION AND BENDING
}

\author{
Azam Tafreshi $\quad$ School of Mechanical, Aerospace and Civil Engineering (MACE) \\ The University of Manchester, P.O.Box 88 \\ Sackville Street, Manchester M60 1QD \\ azam.tafreshi@manchester.ac.uk
}

\begin{abstract}
Composite cylindrical shells and panels are widely used in aerospace structures. These are often subjected to defects and damage from both in-service and manufacturing events. Delamination is the most important of these defects. This paper deals with the instability analysis of delaminated composite cylindrical shells subject to pure bending and also combined bending and axial compression, using the finite element method. The combined double-layer and single-layer of shell elements are employed, which in comparison with the three-dimensional finite elements requires less computing time and space for the same level of accuracy. The effect of contact in the buckling mode has been considered, by employing contact elements between the delaminated layers. The interactive buckling curves and postbuckling response of delaminated cylindrical shells have been obtained. In the analysis of post-buckled delaminations, a study using the virtual crack closure technique has been performed to find the distribution of the strain energy release rate along the delamination front. The results show that under pure bending, laminated cylindrical shells are more sensitive to the presence of delamination, than they are under pure axial compression. It was also observed that the effects of delamination are more apparent when the composite cylindrical shells are subjected to combined axial compression and bending. In this case, with a slight increase of the applied bending moment, the strain energy release rate distribution on the compressive side of the cylinder changes drastically.

Keywords: Delamination, finite element method, buckling and postbuckling
\end{abstract}




\section{INTRODUCTION}

The phenomenon of progressive failure in laminated composite structures is yet to be understood, and as a result, reliable strategies for designing optimal composite structures for desired life and strength are in demand [1-2].

Laminated composite materials are increasingly being used in the aerospace, marine, automobile and other engineering industries. This is due to their high strength-to-weight and stiffness-to-weight ratios. However, due to the lack of through-the-thickness reinforcement, structures made from these materials are highly liable to failures caused by delamination. Therefore, within a design process, a structure's resistance to delamination should be addressed to maximize its durability and damage tolerance. Delaminations in composite cylinders may be due to manufacturing defects, transportation impacts and environmental effects during their service life. The presence of delaminations leads to a reduction in the overall buckling strength of the laminated composite cylindrical shells [3$6]$.

For the past two decades analytical and numerical analyses have been carried out by many researchers to analyse delaminated composite structures, considering their buckling and post-buckling behaviour[7-8]. Almost all of the papers on delamination buckling deal with beams and flat plates.[6, 9-17]. The early work belongs to Chai et al.[9] who characterized the delamination buckling models by the delamination thickness and the number of delaminations through the laminate thickness. Due to its mathematical complexity and modelling, very limited information on the subject of delamination buckling of cylindrical shells and panels is currently available [3-5, 18-28]. The most comprehensive analytical study is by Simitses et al[19-21]. Simitses et al [19-21] analytically predicted delamination buckling of cylindrical shells and panels. The load cases considered in their study were uniform axial compression and uniform external pressure, applied individually. For both cases they did not account for the contact between delaminated layers during buckling.

Thin-walled circular cylindrical shells are very often loaded in such a way that the three buckling membrane forces: axial compression, circumferential compression and shear, are 
not applied individually but in combination. Therefore, a designer not only has to consider the buckling characteristics of a cylindrical shell under fundamental loading conditions, but also the buckling interactions. There is a reasonable amount of work on the instability response of intact laminated cylindrical shells under axial compression, external pressure, bending and torsion, applied individually. Thus, very limited information on the instability response of composite shells under combined loading is available and most of it does not consider the postbuckling response which, if considered, will result in significant cost savings. Most of the published data deals with the buckling response of compressionloaded composite shells. Ref[29] consists of a comprehensive study on the stability of metallic cylindrical shells under combined loading.

In the recent study by the author [30], a numerical study using the non-linear finite element analysis was carried out to investigate the response of perfect and imperfect composite cylindrical shells subject to combined loading. The interaction buckling curves of perfect composite cylinders subject to different combinations of axial compression, torsion, bending and lateral pressure were obtained. The postbuckling analysis of composite cylinders with geometric imperfections of eigenmode-shape was carried out to study the effect of imperfection amplitude on the critical buckling load.

Despite the relatively widespread attention given to the problem of delamination in laminated composites, to the author's knowledge, there is hardly any information available on the effect of delamination in a composite cylindrical shell structure under combined loading.

In references [4-5], delamination buckling and postbuckling of composite cylindrical shells under axial compression [5] and external pressure [4], applied individually, were considered. For both loading cases, the effect of contact between the delaminated layers was taken into account. In another study the effects of delamination on the buckling and postbuckling behaviour of composite cylindrical shells subject to combined axial compression and lateral pressure were investigated [3]. The interaction buckling curves of intact and delaminated composite cylindrical shells relating the lateral pressure and axial 
compression were obtained. In the analysis of post-buckled delaminations, a study using the virtual crack closure technique [31] was performed to find the distribution of the local strain energy release rate(SERR) along the delamination front. For the sake of comparison some of those results are also presented in this paper.

This paper deals with the computational modelling of delamination buckling and postbuckling of laminated composite cylindrical shells subjected to pure bending and also combined axial compression and bending using ABAQUS [32]. Some results are also provided on the influence of the internal pressure on the buckling under the action of combined axial compression and bending.

\section{GEOMETRY, MATERIALS AND LOADING CONDITIONS}

A typical delaminated circular cylindrical shell with length $L$, radius $r$, and thickness $t$ is shown in Fig.1a. Fig. 1b shows a differential element of an intact cylindrical shell segment with the coordinate axes. The axial coordinate is $\mathrm{x}$, the circumferential coordinate is $\mathrm{y}$, and the through-the-thickness coordinate normal to the shell middle surface is $\mathrm{z}$. The circumferential coordinate is replaced by $\mathrm{y}=\mathrm{r} \beta$.

The rectangular delamination $\left(\mathrm{L}_{\mathrm{d}} \times \mathrm{b}\right)$ is located symmetrically with respect to both ends of the shell, where $L_{d}$ is in the axial direction and $b=r \alpha$ is in the circumferential direction. Angle $\alpha$ denotes the region of the delamination. $t_{1}$ and $t_{2}$ are the thicknesses of the upper and lower sublaminantes, respectively. The nondimensional parameters $h=t_{1} / t$ and $a=L_{d} / L$ are used to describe the delamination thickness and length, respectively.

The loadings considered in this study are axial compressive load and bending, either applied individually or in combination. The axial $\operatorname{load}(\mathrm{R})$ is a uniform compressive force applied at the ends of the shell. The pure bending is applied by using the coupling technique in ABAQUS, in which all the nodes on each end cross-section are kept in the same respective plane. Then two opposite concentrated loads were applied in the $\mathrm{x}$ direction to simulate bending. This method of loading ensures that a shell is subjected to pure bending and that the cross-sections remain on the same planes after deformation, 
which properly models the actual experimental conditions. Also, the two concentrated loads applied would not create a very high local stress concentration. In this study the delamination surface is always symmetric with respect to the plane of bending moment. The materials selected throughout this study and their engineering constants are shown in Table 1.

Figs.1c-1e show the first buckling mode of a graphite-epoxy cylindrical shell(L/r=5, $r / t=30)$ with the stacking sequence of $[0 / 90 / 0]_{10 T}$ under pure bending, pure axial compression and in combination, respectively.

\section{FINITE ELEMENT MODELLING AND VERIFICATION}

The following explains the FE modelling, buckling and postbuckling procedures and also the method employed for calculation of the strain energy release rate (SERR) in this study, respectively.

The displacement field for an intact cylindrical shell, according to a first order shear deformation theory, is given by

$$
\begin{aligned}
& \mathrm{u}_{\mathrm{x}}=\mathrm{u}_{\mathrm{x}}^{0}+\mathrm{z} \psi_{\mathrm{x}} \\
& \mathrm{u}_{\mathrm{y}}=\mathrm{u}_{\mathrm{y}}^{0}+\mathrm{z} \psi_{\mathrm{y}} \\
& \mathrm{u}_{\mathrm{z}}=\mathrm{u}_{\mathrm{z}}^{0}
\end{aligned}
$$

$\mathrm{u}_{\mathrm{x}}, \mathrm{u}_{\mathrm{y}}, \mathrm{u}_{\mathrm{z}}$ are the displacements (in the $\mathrm{x}, \mathrm{y}$ and $\mathrm{z}$ directions, respectively) and $\psi_{\mathrm{x}}, \psi_{\mathrm{y}}$ are the rotations (about $\mathrm{y}$ and $\mathrm{x}$ axes, respectively), at arbitrary locations with the distance $\mathrm{z}$ to the shell's mid-surface. $\mathrm{u}_{\mathrm{x}}^{0}, \mathrm{u}_{\mathrm{y}}^{0}, \mathrm{u}_{\mathrm{z}}^{0}$ are the mid-surface displacements of the shell in the respective directions.

For the analysis of a delaminated cylinder, the intact regions can be represented by a single-layer of shell elements, whereas the delaminated regions can be modelled by upper and lower sublaminates that are connected by contact elements. For the interface region, a modified version of the sublaminate connection method, based on Eq.(1), must be employed. Therefore, also the rotations $\left(\psi_{\mathrm{x}}, \psi_{\mathrm{y}}, \psi_{\mathrm{z}}\right)$ of all the nodes of the stacked layers at 
the transition border are coupled in addition to the displacements $\left(\mathrm{u}_{\mathrm{x}}, \mathrm{u}_{\mathrm{y}}, \mathrm{u}_{\mathrm{z}}\right)$. Thus, the midsurfaces of the sublaminates of the delaminated and the mid-surface of the laminate of the intact area are coupled by the following set of equations:

$$
\begin{aligned}
& \mathrm{u}_{\mathrm{x}}^{1,0}-\left(\frac{\mathrm{t}_{1}}{2}\right) \psi_{\mathrm{x}}^{1}=\mathrm{u}_{\mathrm{x}}^{2,0}+\left(\frac{\mathrm{t}_{2}}{2}\right) \psi_{\mathrm{x}}^{2}=\mathrm{u}_{\mathrm{x}}^{0} \\
& \mathrm{u}_{\mathrm{y}}^{1,0}-\left(\frac{\mathrm{t}_{1}}{2}\right) \psi_{\mathrm{y}}^{1}=\mathrm{u}_{\mathrm{y}}^{2,0}+\left(\frac{\mathrm{t}_{2}}{2}\right) \psi_{\mathrm{y}}^{2}=\mathrm{u}_{\mathrm{y}}^{0} \\
& \mathrm{u}_{\mathrm{z}}^{1,0}=\mathrm{u}_{\mathrm{z}}^{2,0}=\mathrm{u}_{\mathrm{z}}^{0} \\
& \psi_{\mathrm{x}}^{1}=\psi_{\mathrm{x}}^{2}=\psi_{\mathrm{x}}^{0} \\
& \psi_{\mathrm{y}}^{1}=\psi_{\mathrm{y}}^{2}=\psi_{\mathrm{y}}^{0} \\
& \psi_{\mathrm{z}}^{1}=\psi_{\mathrm{z}}^{2}=\psi_{\mathrm{z}}^{0}
\end{aligned}
$$

The selection of the mid-surface as a reference surface in a shell element is due to tradition and the ease of defining bending and shear rigidities. However, for composite laminates with delaminations, it leads to the complexity of using constraint equations (Eq. 2) to maintain compatibility of displacements on the delaminated front. The other disadvantage is for use with the virtual crack closure technique (VCCT) for calculation of the strain energy release rate(SERR). An alternative method, which overcomes these difficulties and also simplifies the mesh generation, is to choose the reference surface at an arbitrary position within the shell's thickness. According to the first order, shear deformation theory (Eq. 1), the deformation at any position within the thickness direction can be expressed by the deformation at any chosen surface, not necessarily the shell's mid-surface.

Fig. 2a shows the close-up view of the FE model used in the present study. This FE model is also a combination of double-layer and single-layer of shell elements; however, the delaminated surface is chosen as the reference surface for both the intact and delaminated regions. In the delaminated region, nodes are separately defined on the upper and lower sublaminates although they may have the same coordinates. Gap elements are placed between the corresponding nodes of the upper and lower sublaminates to avoid the interpenetration of the delaminated layers. Within the intact and delaminated regions, the nodes located on the reference surface are offset from the mid-surfaces of the corresponding shells, either in the positive or negative direction. To maintain compatibility 
of displacements on the delaminated front, the nodes of the intact and delaminated regions are tied together to have equal deformations.

The first stage in the simulation of the delaminated cylinder subject to pure bending is a linear eigenvalue buckling analysis. In simple cases, linear eigenvalue analysis may be sufficient for design evaluation; but geometrically nonlinear static problems sometimes involve buckling or collapse behaviour, where the load-displacement response shows a negative stiffness and the structure must release strain energy to remain in equilibrium. Several methods [33-34] are available for modelling such behaviour. One method is to treat the buckling response dynamically, therefore, modelling the response, with inertia effects included, as the structure snaps. Another approach for finding static equilibrium states, during the unstable phase of the response, is the modified Riks method available in ABAQUS. The Riks method is based on moving with fixed increments along the static equilibrium path in a space defined by the displacements and a proportional loading parameter. This method is used for cases where the loading is proportional, therefore, the load magnitudes are governed by a single scalar parameter. Arc length methods such as the Riks method are global load-control methods that are suitable for global buckling and postbuckling analyses; they do not function well when buckling is localized. Another method is to use dashpots to stabilize the structure during a static analysis. ABAQUS offers an automated version of this stabilization approach for the static analysis procedures. It should be noted that the initial small deflection that is necessary to make the structure buckle was established by imposing an imperfection to the original mesh. The applied imperfection rested on an eigenmode buckling analysis of the structure where the maximum initial perturbation was $5 \%$ of the thickness of the shell. This method has been successfully used in the earlier studies of the author[3-4,30].

The case of combined bending and axial compressive load is carried out in two steps. In the first step a live bending moment is applied to the shell, and in the second step the critical axial buckling load is determined. For the postbuckling analysis, the bending load is applied as a live load in the first step, and in the next step, the axial compressive load is set to increase up to 1.2 times the critical axial compressive load of a perfect 
cylinder subjected to axial compressive load alone. Using ABAQUS it is also possible to apply an axial compressive load in the first step and to determine the critical bending moment in the following step. The results will be almost identical.

The virtual crack closure technique (VCCT) is used to calculate the strain energy release rate (SERR). The nodal forces at the crack front and the displacements behind the crack front are used to calculate SERR [31]. Fig. 2b shows a model of a pair of four elements in the upper and lower sublaminates at the delamination front. The crack front is located beneath nodes $c_{j}(j=1,5)$. The components of the strain energy release rate for the three modes for a typical element are

$$
\begin{aligned}
& G_{I}=\frac{1}{2 \Delta A}\left\{F_{Z_{c_{3}}}\left(w_{a_{3}}-w_{A_{3}}\right)+F_{Z d_{2}}\left(w_{b_{2}}-w_{B_{2}}\right)+\frac{1}{2}\left[F_{Z c_{2}}\left(w_{a_{2}}-w_{A_{2}}\right)+F_{Z c_{4}}\left(w_{a_{4}}-w_{A_{4}}\right)\right]\right\} \\
& G_{I I}=\frac{1}{2 \Delta A}\left\{F_{X c_{3}}\left(u_{a_{3}}-u_{A_{3}}\right)+F_{X d_{2}}\left(u_{b_{2}}-u_{B_{2}}\right)+\frac{1}{2}\left[F_{X c_{2}}\left(u_{a_{2}}-u_{A_{2}}\right)+F_{X c_{4}}\left(u_{a_{4}}-u_{A_{4}}\right)\right]\right\} \\
& G_{I I I}=\frac{1}{2 \Delta A}\left\{F_{Y c_{3}}\left(v_{a_{3}}-v_{A_{3}}\right)+F_{Y d_{2}}\left(v_{b_{2}}-v_{B_{2}}\right)+\frac{1}{2}\left[F_{Y c_{2}}\left(v_{a_{2}}-v_{A_{2}}\right)+F_{Y c_{4}}\left(v_{a_{4}}-v_{A_{4}}\right)\right]\right\}
\end{aligned}
$$

An example of a delaminated cylindrical shell made of isotropic material with clamped ends under axial compression, similar to the model employed by Simitses et al[20], was presented in Ref.[5] to validate the proposed FE modelling approach. The delamination was located symmetrically with respect to both ends of the shell and it extended along its entire circumference. The dimensions of the shell are such that $\mathrm{L} / \mathrm{r}=5$ and $\mathrm{r} / \mathrm{t}=30$. The numerical results of variation of critical load with delamination length and delamination thickness, obtained using the present method, were compared with those obtained by Simitses et al[20], as shown in Fig. 3. The critical loads $\left(\mathrm{R}_{\mathrm{cr}}\right)$ are normalized with respect to the critical load of an intact cylinder $\left(\mathrm{R}_{\mathrm{c}}\right)$. It is shown that although Simitses et al [20] did not account for the contact, between delaminated layers during buckling, their results look reasonable. Similar results were obtained for two composite cylindrical shells made of graphite-epoxy and kevlar-epoxy laminates[5]. The cylinders had the same geometry and boundary conditions as the isotropic cylinder studied earlier. The cross-ply laminates had the stacking sequence of $\left[0^{\circ} / 90^{\circ} / 0^{\circ}\right]_{10}$. The buckling curves of the delaminated 
composite cylinders with the delamination thicknesses of $h=0.3$ and $h=0.5$ are also included in Figs. 3a-3c. The results for the delamination thickness of $h=0.1$ were obtained but are not presented. However, for $h=0.1$, the trends of the variation of buckling loads, with respect to the delamination length in the laminated and isotropic cylindrical shells, are similar.

\section{RESULTS AND DISCUSSION}

An example of a laminated cylindrical shell, with clamped ends, subjected to bending and which is also under simultaneous axial compression and bending is presented here. The loading case of combined axial compression, bending and internal pressure is also considered. The delamination region has a rectangular shape and is placed on the compressive side of the cylinder, when subjected to bending. It is located symmetrically with respect to both ends of the shell and it is also symmetric with respect to the plane of the bending moment. The dimensions of the shell employed throughout this study are such that $\mathrm{L} / \mathrm{r}=5$ and $\mathrm{r} / \mathrm{t}=30$, unless stated otherwise. The delamination length (a) and delamination width $(\alpha)$ vary as $0.04<\alpha<0.5$ and $\pi / 12<\alpha<\pi$, respectively. The presented results include the delamination thicknesses of $h=0.5$ and 0.3 , respectively. Throughout this study eight noded shear deformable shell element with reduced integration, designated S8R in ABAQUS, which allows large rotations and small strains are employed for the analysis.

Fig. 4 shows the effect of delamination size on the critical buckling load of the cylindrical shell subjected to pure bending, when $h=0.5$. Two-dimensional and three-dimensional views of the variation of the critical bending moment $\left(\mathrm{M}_{\mathrm{cr}} / \mathrm{M}_{\mathrm{c}}\right)$ with respect to the delamination width $(\alpha)$ and delamination length (a) are presented in Figs.4a-4c. A similar set of results for the delamination thickness of $h=0.3$ is shown in Fig.5. The results show that for a very small values of the delamination area, the presence of the delamination has no significant effect on the critical loads. For a large delamination area, especially when the delaminated layer is closer to the free surface of the laminate $(h<0.1)$, the critical load is very small. It was also observed that for $h>0.1$, the higher the delamination thickness is, the

lower the critical buckling load is. It can be said that the lowest critical buckling load 
occurs when the delamination is located at the laminate's mid-surface. For a very large delamination area where $a>0.375$ and $\alpha>\pi / 2$, the critical buckling load is almost independent of the delamination size and mainly depends on the delamination thickness. It was also observed that for $a<0.375$ and $\alpha<\pi / 2$, for two models with equal areas of delamination, the delamination with the larger width creates a slightly lower buckling load. Fig, 4d shows the first buckling mode of two laminated cylinders with equal areas of delamination, but having different delamination lengths and widths. It can be observed that the cylinder with the larger delamination width, not only has a slightly lower buckling load but, also has a different buckling shape. The cylinder with the larger delamination width buckles mainly locally, but the buckling mode of the cylinder with the larger delamination length is a combination of local and global buckling.

Fig.6 shows the buckling curves of the cylinder with a square delamination subject to axial compression and bending, applied individually. The parameter $A^{*}=A_{d} / A$ shows the fraction of the total area of the cylinder, where $A_{d}$ is the delamination area and $A$ is the total surface area of the cylinder. The variation of the normalized buckling loads $\left(\mathrm{M}_{\mathrm{cr}} / \mathrm{M}_{\mathrm{c}}\right)$ and $\left(\mathrm{R}_{\mathrm{cr}} / \mathrm{R}_{\mathrm{c}}\right)$, respectively, with respect to the delamination area $\mathrm{A}^{*}$ shows that for very small delamination areas the presence of the delamination has small effect on the critical buckling loads in both loading cases. However, with the increase of the delamination area, the critical load of the cylinder subject to bending alone drops dramatically, especially when the delamination is placed at the plate's mid-surface. For larger delamination areas when $\mathrm{A}^{*}>0.2$, the critical buckling load is almost independent of the delamination size and mainly depends on the delamination thickness.

In Ref.[30] the interaction buckling curves of perfect and imperfect composite laminated cylinders subject to combined axial compression and bending are presented. For the selected geometries and materials, it was observed that the relationship between critical loads of cylinders under compression and bending is almost linear, except for those of the laminated cylinder under a very high compression load. The rest of this study has been performed on the graphite-epoxy cylindrical shell $(\mathrm{L} / \mathrm{r}=5, \mathrm{r} / \mathrm{t}=30)$ with the stacking sequence of $[0 / 90 / 0]_{10 \mathrm{~T}}$, subject to combined bending and axial compression. Fig. 7a 
shows the interaction buckling curve, relating $\left(R / R_{c}\right)$ and $\left(M / M_{c}\right)$, of the cylinder with square delamination, when $\mathrm{h}=0.5$. The delamination area varies as $0.0023<\mathrm{A} *<0.333$. The interaction curve of the intact cylinder is also included in Fig.7a. The results show that, for a very small delamination area $\left(\mathrm{A}^{*}<0.0023\right)$, the presence of delamination does not appreciably alter the interaction buckling curve of an intact cylinder. For small delamination areas $\left(\mathrm{A}^{*}<0.008\right)$ the buckling curve has a linear variation except those of the laminated cylinder under a very high compression load. For large delamination areas ( $\left.A^{*}>0.008\right)$, the shape of the interaction curve has almost a linear variation. For very large delamination areas $\left(\mathrm{A}^{*}>0.2\right)$, the interaction curve is almost independent of the increase of the delamination area.

Similar results are produced for the same delaminated cylinder with the delamination thickness of $h=0.3$. See Fig. $7 b$. It can be observed that for a very small delamination area $\left(\mathrm{A}^{*}<0.0023\right)$ the presence of delamination does not appreciably alter the interaction buckling curve of an intact cylinder. However, the critical buckling load drops dramatically with the increase of the delamination area when $\mathrm{h}=0.3$. Therefore, the effect of delamination is more apparent when the cylinder is subject to bending and the delamination thickness is closer to the free surface of the cylinder $(\mathrm{h}<0.5)$.

Next, the effect of the internal pressure on the interaction buckling curve of the cylinder, axial compression vs bending, was investigated. Each analysis was performed in three different steps. Initially a live pressure load was applied to the shell, then a bending moment was applied to the pressurized shell in the second step and in the final step the critical axial compressive load was determined. Using ABAQUS it is also possible to apply the bending moment in the first step and the pressure in the second step and finally determine the critical axial compressive load. The results would be identical.

Figs. 8a-b show the interaction buckling curves, axial compression $\left(R / R_{c}\right)$ vs bending $\left(\mathrm{M} / \mathrm{M}_{\mathrm{c}}\right)$, at different pressure levels for the cylinder with a square delamination, $\mathrm{A}^{*}=0.02$, when $\mathrm{h}=0.5$ and 0.3 , respectively. The pressure level varies from $\mathrm{P}=0$. to $\mathrm{P}=0.5 \mathrm{P}_{\mathrm{c}}$. It can be seen that for the delamination thickness of $\mathrm{h}=0.5$, the internal pressure slightly increases 
the critical buckling load and onset of the buckling mode. For $\mathrm{h}=0.5$, the interaction curves have almost a linear variation. However, for the delamination thickness of $h=0.3$, the internal pressure greatly improves the interaction buckling curves. The results show that for the delamination thickness of $\mathrm{h}<0.5$, the increase of the internal pressure would significantly increase the critical buckling load and onset of the buckling mode.

Fig.8c shows the buckling mode shapes of the cylinder with a square delamination $\left(\mathrm{A}^{*}=0.02\right)$ under combined axial compression and bending, with and without internal pressure, for $\mathrm{h}=0.3$ and 0.5 , respectively. For the sake of comparison, each cylinder was initially subjected to an axial compressive load of $\mathrm{R}=0.5 \mathrm{Rc}$ in the first step, and then the corresponding buckling moment was obtained in the second step. It can be observed that for the same axial compressive load when $h=0.5$, the internal pressure slightly increases the critical buckling moment. However, the mode shapes of the pressurized and nonpressurized cylinders in this case are almost identical. For $\mathrm{h}=0.3$ and for the same axial compressive load, the internal pressure significantly increases the critical bending moment. It can also be observed that, in this case, the non-pressurised cylinder buckles mainly locally while the buckling shape of the pressurised cylinder is a combination of local and global buckling.

Next, the postbuckling analysis was performed on the cylinder with the delamination thickness of $\mathrm{h}=0.5$ and with three different delamination lengths of $\mathrm{a}=0.042,0.08,0.125$, respectively, extended along the entire circumference. The cylinder is initially subjected to a preloading of $\mathrm{M}=0.25 \mathrm{Mc}$. For the postbuckling analysis, the bending moment was applied as a live load in the first step, and in the next step, the axial compressive load was set to increase up to 1.2 times the critical axial compressive load of a perfect cylinder subjected to axial compressive load alone. Fig.9a shows the load-shortening response(R/R $\mathrm{R}_{\mathrm{c}}$ vs $U_{x} / t$ ) of the cylinder subject to combined loading. $U_{x}$ is the axial displacement of the cylinder. The effect of delamination length on the buckling response is clearly evident. It can be seen that as the delamination length increases, the collapse load drops sharply. This response also shows a dramatic loss of strength after the peak load. The collapse load is the maximum load which the structure can support. 
Fig. $9 \mathrm{~b}$ shows the load-shortening response of the cylinder subject to the preloading of 0.0 , $0.1 \mathrm{M}_{\mathrm{c}}, 0.25 \mathrm{M}_{\mathrm{c}}$ and $0.5 \mathrm{M}_{\mathrm{c}}$, respectively. The cylinder has the delamination length of $\mathrm{a}=0.125$, extended along the entire circumference. The axial compressive load was set to increase up to 1.2 times the critical axial compressive load of a perfect cylinder subjected to axial compressive load alone. The results show that the increase of the preloading value drastically decreases the collapse load of the cylinder.

Fig. 10 shows the strain energy release rate distribution along the crack front of the cylinder with a delamination length of $\mathrm{a}=0.125$, with a preloading of $\mathrm{M}=0.1 \mathrm{Mc}$ at different increments of axial compressive load up to the collapse load. Obviously the higher the axial compressive load, the higher the SERR along the crack front, especially on the compressive side of the cylinder subjected to bending. The numerically negative SERR values express no tendency to grow in the corresponding region. The zero value of SERR indicates that the crack is completely arrested at the corresponding point. It can also be observed that the points with zero values of SERR do not shift with the increase of the axial compressive load. Fig. 11 shows the SERR along the crack front of the cylinder (Fig.10), at the collapse load, for the preloading values of $\mathrm{M}=0 ., 0.1 \mathrm{M}_{\mathrm{c}}, 0.25 \mathrm{M}_{\mathrm{c}}$ and $0.5 \mathrm{M}_{\mathrm{c}}$, respectively. It can be observed that SERR has an almost sinusoidal distribution along the crack front when the cylinder is subjected to axial compressive load alone. The results show that with the increase of the preloading, the SERR changes dramatically on the compressive side of the cylinder, and reduces on the tensile side of the cylinder, as expected. Therefore, in some practical situations when the cylinder is subject to pure bending, once a delamination is identified, it is possible to simply rotate the cylinder to produce a useable cylinder. 


\section{CONCLUDING REMARKS}

One of the most common failure modes for composite structures is delamination. A combined single-layer and double layer of shell elements was employed for the analysis of composite laminated cylindrical shells with delaminations. The effect of contact in the buckling mode has been considered, by employing contact elements between the delaminated layers. The delamination buckling and postbuckling of composite laminated shells under bending alone and also combined axial compressive load and bending was investigated. The total strain energy release rate along the delamination front was evaluated using the virtual crack closure technique. The present method provides an excellent framework for the analysis of delaminated composite shell structures. It gives accurate results with the simplicity of computer modelling, which requires relatively less computer time and space.

The results show that for very small delamination areas, the presence of delamination does not appreciably alter the critical load of a perfect geometry under the same loading condition. The delamination located on the shell's mid-surface creates a lower critical buckling load. However, for larger delamination areas, as the position of delamination moves near the free surface of the laminate, the critical load is very small. In this case the critical load is not related to the load-carrying capacity of the structure and failure will be due to the delamination growth, which depends on the fracture toughness of the material. The results show that under pure bending, laminated cylindrical shells are more sensitive to the presence of delamination than they are under pure axial compression. It was observed that the effects of delamination are more apparent when the composite cylindrical shells are subject to combined axial compression and bending. In this case with a slight increase of the applied bending moment, the SERR, on the compressive side of the cylinder, will change dramatically.

The interaction buckling curves of intact and delaminated composite cylindrical shells, relating the axial compressive load and bending, were obtained. The effect of the internal pressure on the interaction buckling curves was also studied. The results show that, for a very small delamination area, the presence of delamination does not appreciably alter the 
interaction buckling curve of an intact cylinder. For small delamination areas the interaction curve has a linear variation except those of the laminated cylinder under a very high compression load. When delamination is placed on the laminate's mid-surface, for larger delamination areas, the shape of the interaction curve has almost a linear variation, but for very large delamination areas, the interaction curve is almost independent of the increase of the delamination area. When delamination is located closer to the free surface of the cylinder, the internal pressure can greatly increase the critical load of the cylinder and, therefore, can significantly change the interactive buckling curve. The results show that the increase of the delamination area greatly reduces the collapse load of the structure and the structure shows a dramatic loss of strength after the peak load.

In the previous studies of the author it was observed that the buckling load was highly influenced by the laminate stacking sequence. Hence, there are stacking sequences that favour delamination growth and others that exhibit high resistance against the crack extension. Therefore, a laminate can be tailored to delamination growth resistance. Hence, the study to determine the influence of stacking sequence on SERR distribution and delamination growth in laminated composite shells under combined loading needs further investigation. The method used in the paper can be easily applied for the analysis of the delaminated composite cylinders with different stacking sequences. 


\section{REFERENCES}

1. Tafreshi, A. " Shape sensitivity analysis with respect to the positioning of features in composite structures using the boundary element method", Engineering Analysis with Boundary Elements, 2006; 30(1), 1-13

2. Tafreshi, A., "Optimum shape design of composite structures using the boundary element method", AIAA Journal, 2005; 43(6), 1349-1359

3. Tafreshi, A. "Delamination buckling and postbuckling in composite cylindrical shells under combined axial compression and external pressure", Journal of Composite structures, 2006; 72(4), 401-418

4. Tafreshi, A., "Delamination buckling and postbuckling in composite cylindrical shells under external pressure", Thin-walled structures, 42/10(2004), 1379-1404

5. Tafreshi, A., "Efficient modelling of delamination buckling in composite cylindrical shells under axial compression”, Composite structures, 64(2004), 51120

6. Tafreshi, A. and Oswald T., "Global buckling behaviour and local damage propagation in composite plates with embedded delaminations", International Journal of Pressure Vessels and Piping, 2003, 80(1), 9-20

7. Bolotin, V.V., "Delamination in composite structures: its origin, buckling, growth and stability", Composites: Part B, 1996; 27B: 129-45

8. T.E.Tay, "Characterization and analysis of delamination fracture in composites: An overview of developments from 1990-2001”, Applied Mechanics Review., 2003; 56(1): 1-31

9. Chai, H., Babcock, C.A. and Knauss, W.G., "One dimensional modelling of failure in laminated plates by delamination buckling", International Journal of Solids and Structures, 1981; 17(11): pp1069-83

10. Klug, J., Wu, X.X. and Sun, C.T., "Efficient modelling of postbuckling delamination growth in composite laminates using plate elements", AIAA J., 1996; 34(1)1: pp178-84

11. Pavier M.J. and Clarke, M.P., "A specialised composite plate element for problems of delamination buckling and growth", Composite Structures, 1996; 34: $43-53$ 
12. Chattopadhyay, A. and Gu, H., "New higher order plate theory in modelling delamination buckling of composite laminates", AIAA J, 1994; 32(8): pp1709-1716

13. Chai, G.B., Banks, W.M. and Rhodes J., "Experimental study on the buckling and postbuckling of carbon fibre composite panels with and without interply disbonds", In: Proceedings of the Institution of Mechanical Engineers: Design in Composite Materials. Mechanical Engineering Publications; 1989, 69-85

14. Whitcomb, J.D., "Three-dimensional analysis of a postbuckled embedded delamination", Journal of Composite Materials, 1989; 23(9); 862-89

15. Hu, N.,"Buckling analysis of delaminated laminates with consideration of contact in buckling mode", International Journal For Numerical Methods in Engineering”, 1999; 44: 1457-79

16. Krueger, R. and O'Brien T.K., "A shell/3D modelling technique for the analysis of delaminated composite laminates", Composites: Part A, 2001; 32: 25-44

17. Kim, H.S., Chattopadhyay, A. and Ghoshal, A., "Characterization of delamination effect on composite laminates using a new generalized layerwise approach", Computers and Structures, 2003; 81: 1555-66

18. Troshin, V.P., "Effect of longitudinal delamination in a laminar cylindrical shell on the critical external pressure", Journal of Composite Materials, 1983; 17(5): 563-7

19. Simitses, G.J. and Chen, Z., "Buckling of delaminated, long, cylindrical panels under pressure", Computers and Structures, 1988; 28(2): 173-84

20. Simitses, G.J., Chen, Z.Q. and Sallam S., "Delamination buckling of cylindrical laminates", Thin-walled Structures, 1991; 11: pp25-41

21. Sallam, S. and Simitses, G.J., "Delamination buckling of cylindrical shells under axial compression", Composite Structures, 1987; 7: 83-101

22. Short,G.J. Guild, F.J. and Pavier,M.J. ,’Delaminations in flat and curved composite laminates subjected to compressive load", Composite Structures, 2002; 58: $249-58$

23. Kutlu, Z. and Chang, F.K., "Composite panels containing multiple through-thewidth delaminations and subjected to compression. Part I: analysis, Composite Structures, 1995; 31: 273-296 
24. Kutlu, Z. and Chang, F.K., "Composite panels containing multiple through-thewidth delaminations and subjected to compression. Part II: experiments \& verification, Composite Structures, 1995; 31: 297-314

25. Naganarayana, B.P., Huang, B.Z. and Atluri S.N., "Multidomain modelling and analysis of delaminated stiffened composite shells", AIAA J., 1996 34(9): 1894-904

26. Gu, H. and Chattopadhyay A., "Delamination buckling and postbuckling of composite cylindrical shells", AIAA Journal, 1996, 34(6): 1279-86

27. Rasheed H.A. and Tassoulas J.L., "Delamination growth in long composite tubes under external pressure", International Journal of Fracture, 2001; 108: 1-23

28. Ju-fen Z., Gang, Z., Howson, W.P. and Williams, F.W., "Reference surface element modelling of composite plate/shell delamination buckling and postbuckling”, Composite Structures, 2003; 61: 255-64

29. Winterstetter, Th. A. and Schmidt, H., "Stability of circular cylindrical shells under combined loading", Thin-walled structures, 40, 2002, 893-909

30. Tafreshi, A. and Bailey, C.G., "Instability of imperfect composite cylindrical shells under combined loading", Composite Structures, In Press

31. Shivakumar, K.N., Tan, P.W. and Newman Jr J.C., "A virtual crack closure technique for calculating stress intensity factors for cracked three dimensional bodies", International Journal of Fracture, 1988; 36: 43-50

32. ABAQUS User's Manual, Version 6.4, Hibbit, Karlson and Sorenson, Inc. 19992005

33. Riks, E., "The application of Newton's method to the problem of elastic stability", J. Appl. Mech., 1972; 39: 1060-6

34. Ramm E., "Strategies for tracing the nonlinear response near limit points. In: Wunderlich E, Stein E, Bathe K.J. editors. Nonlinear Finite element Analysis in Structural Mechanics. Berlin: Springer, 1981 
Table 1 Lamina engineering constants for the selected materials

\begin{tabular}{|l|c|c|c|c|c|}
\hline Material No. & $\mathrm{E}_{\mathrm{L}} / \mathrm{E}_{\mathrm{T}}$ & $v_{\mathrm{LT}}$ & $\mathrm{G}_{\mathrm{LT}} / \mathrm{E}_{\mathrm{T}}$ & $\mathrm{G}_{\mathrm{TT}} / \mathrm{G}_{\mathrm{LT}}$ & $\mathrm{E}_{\mathrm{T}}(\mathrm{GPa})$ \\
\hline Graphite-epoxy & 40 & 0.25 & 0.5 & 1.0 & 5.17 \\
\hline Kevlar-epoxy & 15.6 & 0.35 & 0.56 & 1.0 & 5.5 \\
\hline Boron-epoxy & 11.11 & 0.21 & 0.24 & 1.0 & 18.61 \\
\hline
\end{tabular}




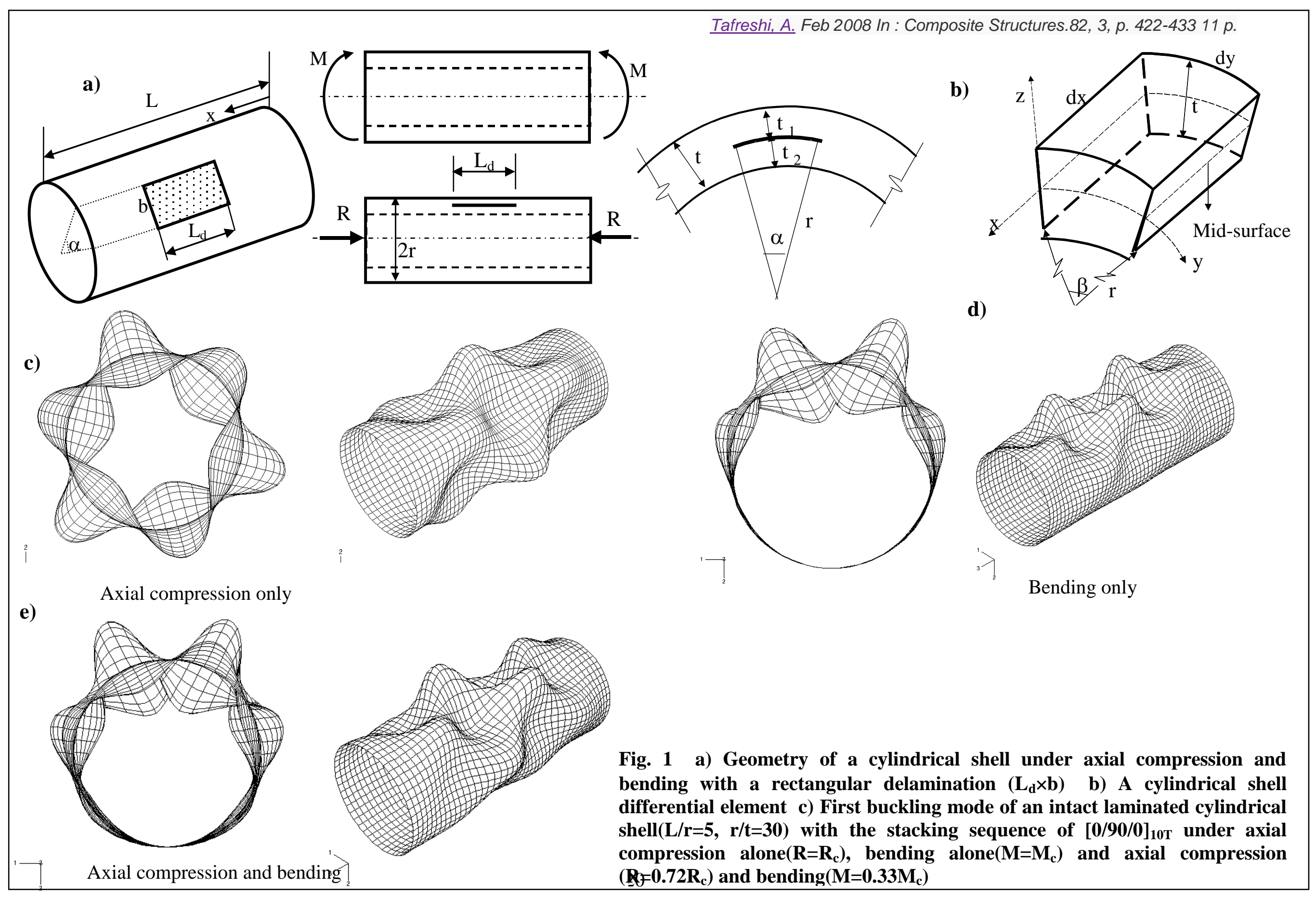


a)

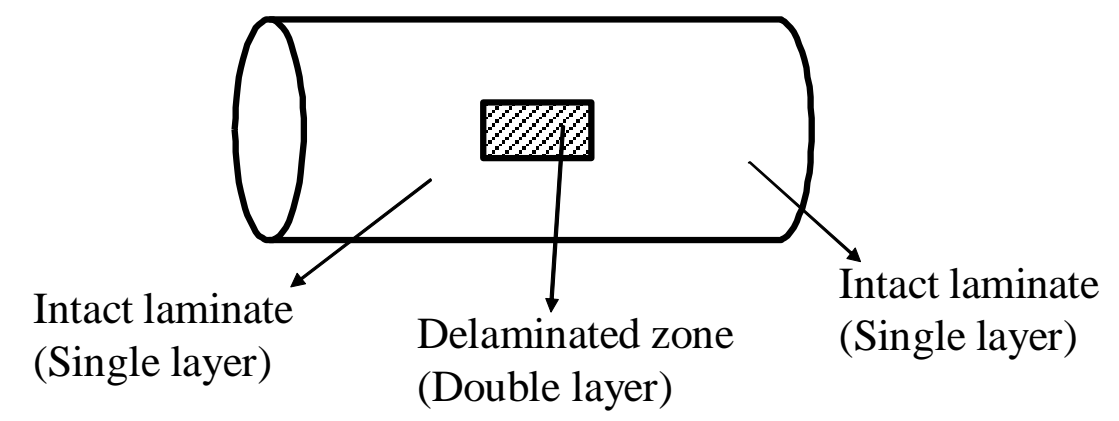

- - Mid-surface

- - Reference surface

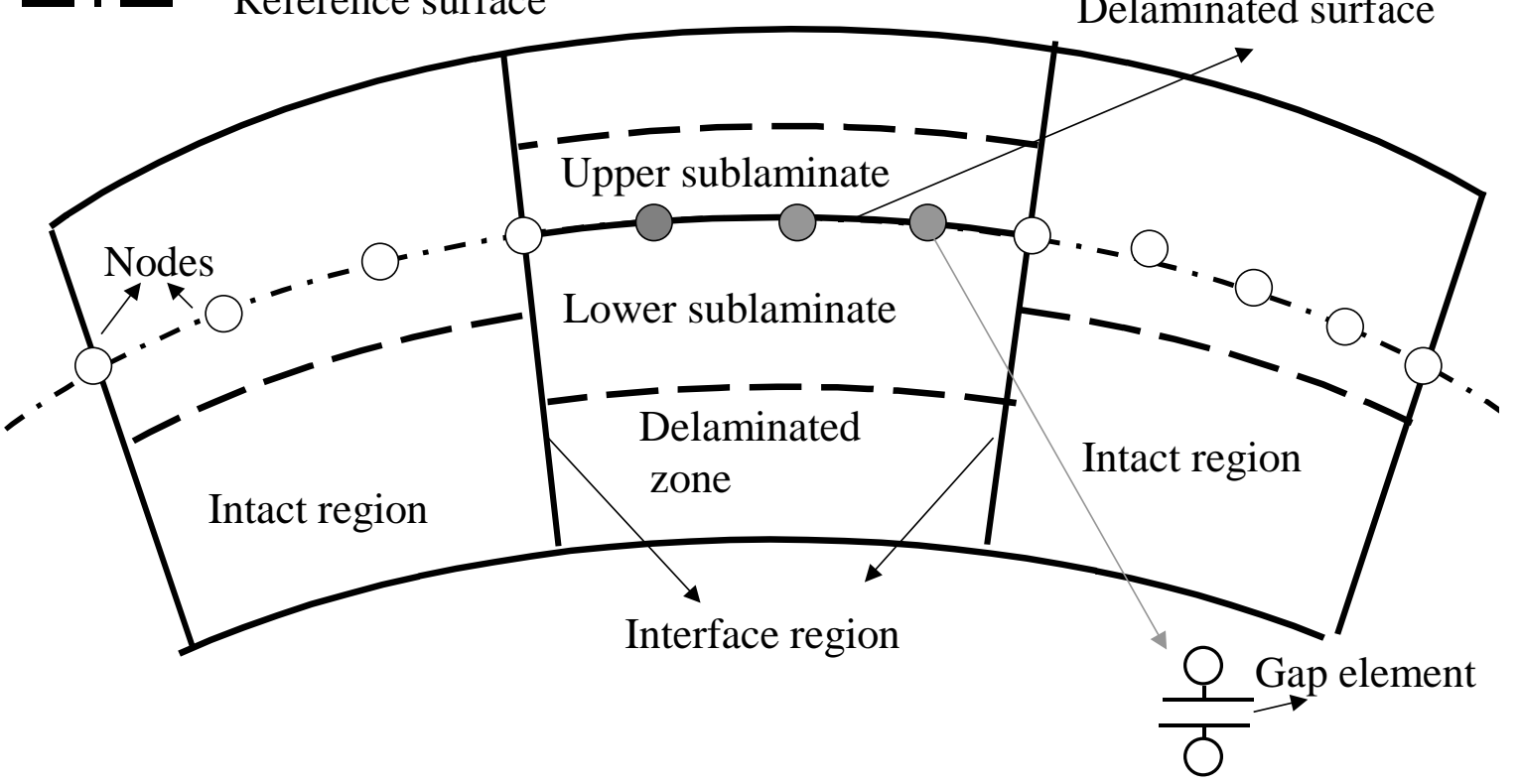

reshi, A. Feb 2008 In : Composite Structures.82, 3, p. $422-43311$ p.

b)

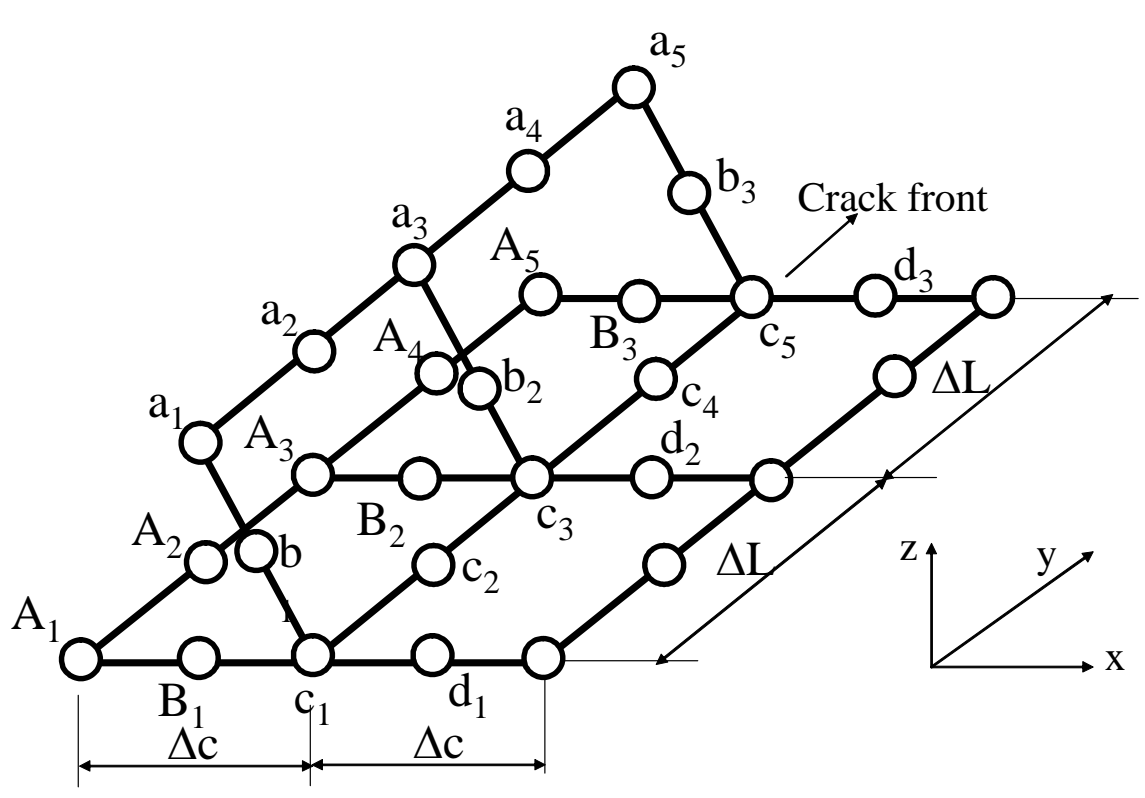

Fig. 2 a) Close-up view of a typical FE model to be used for a delaminated cylindrical shell b) Schematic of delamination front region 


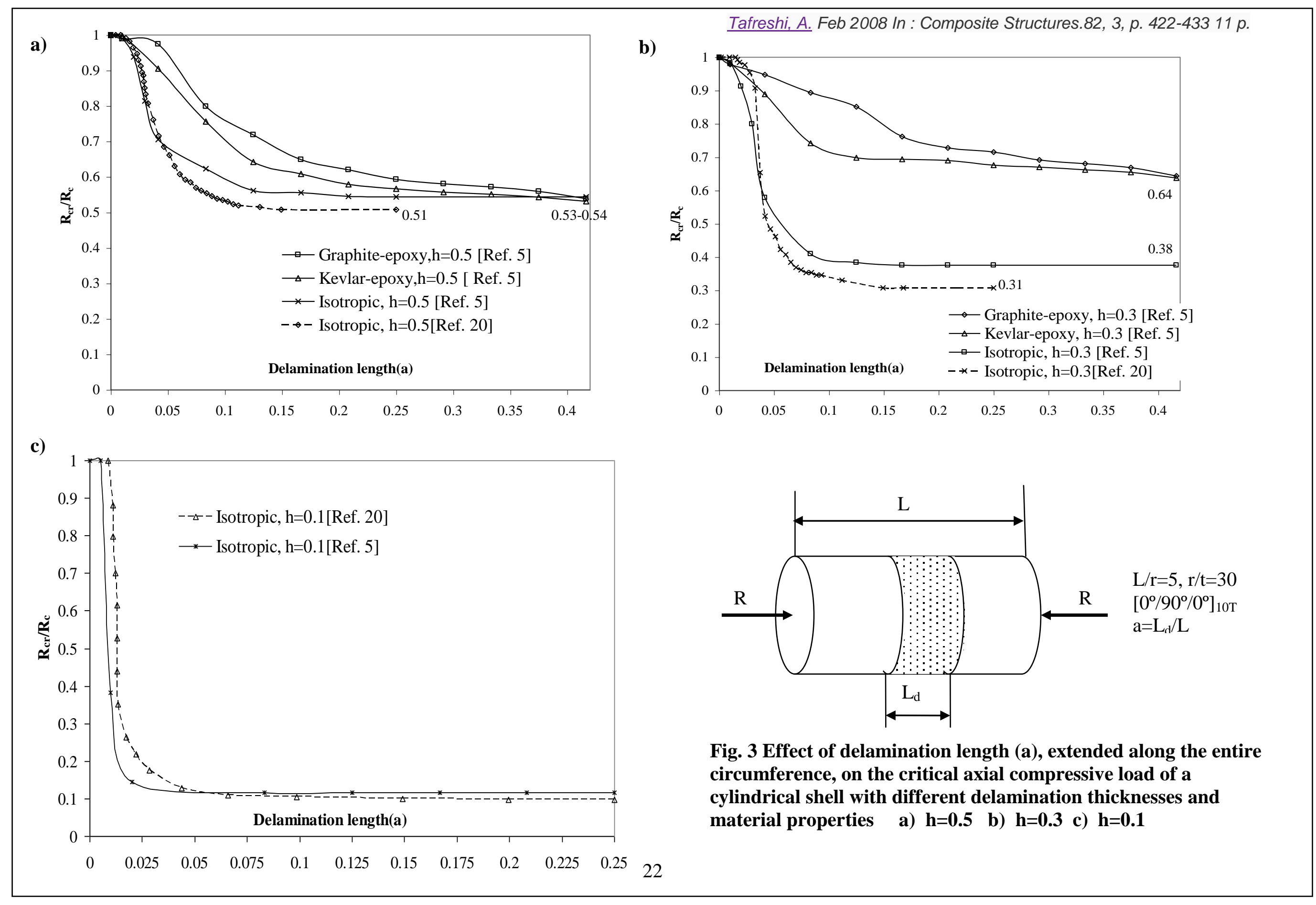




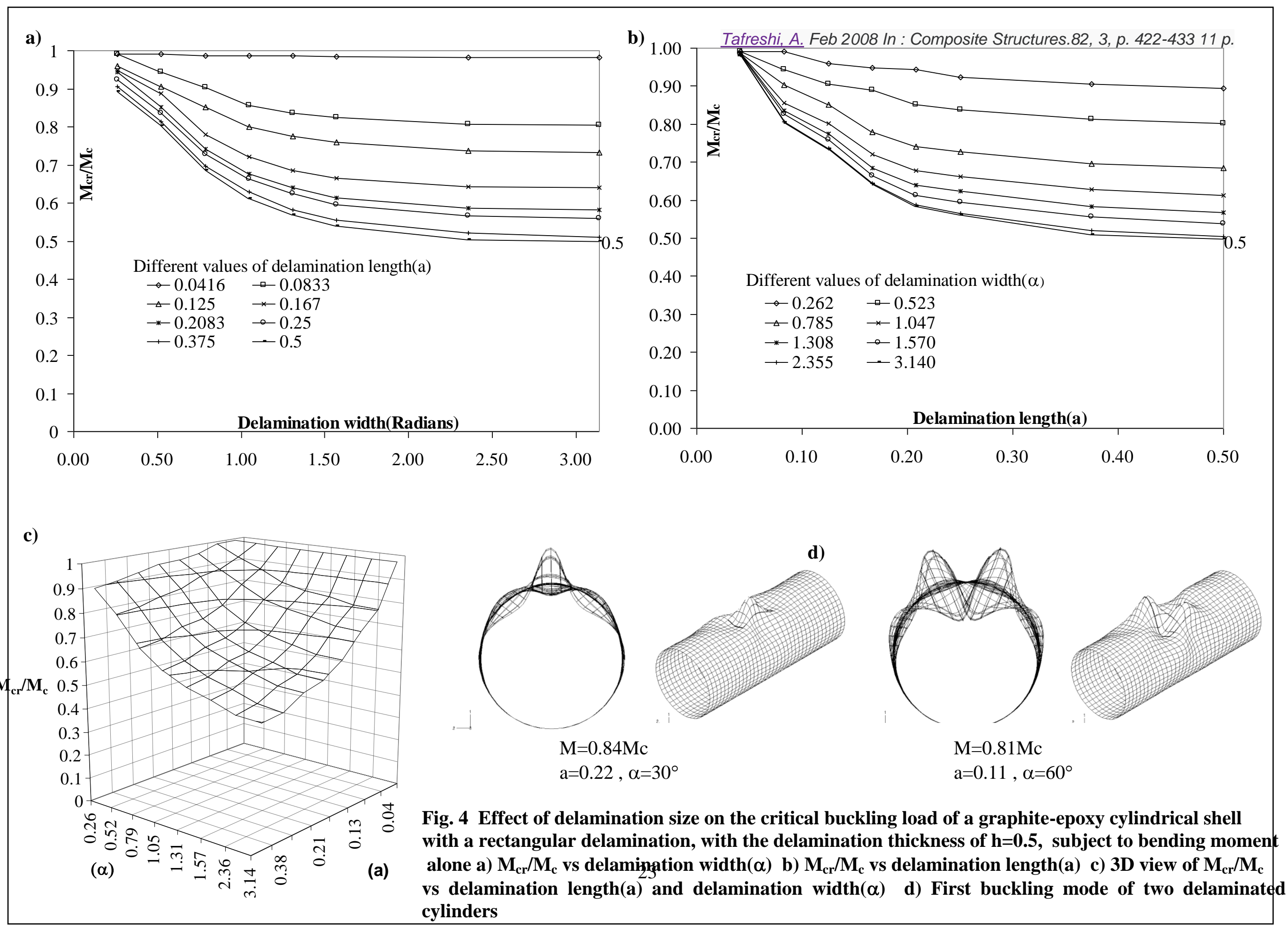




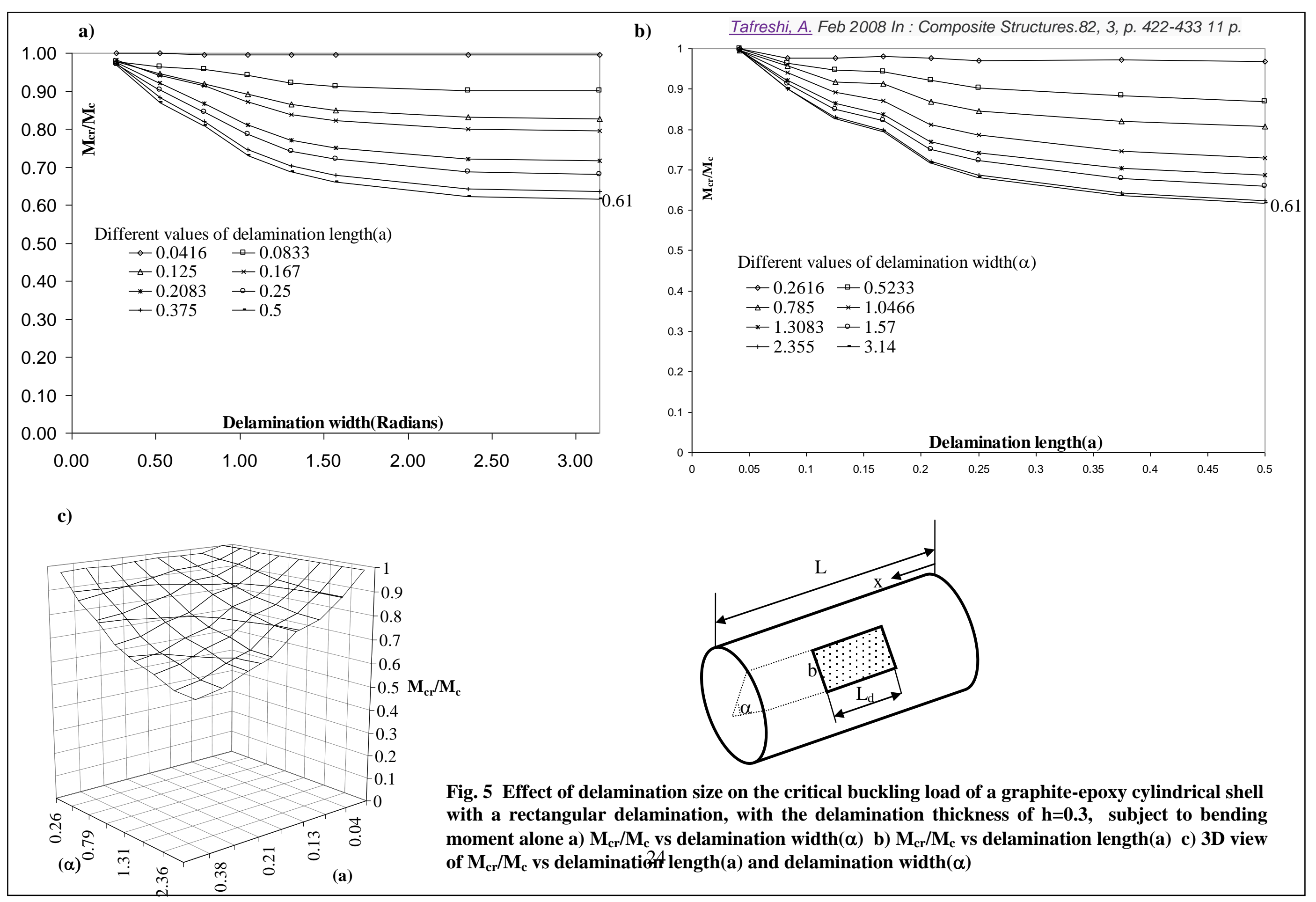




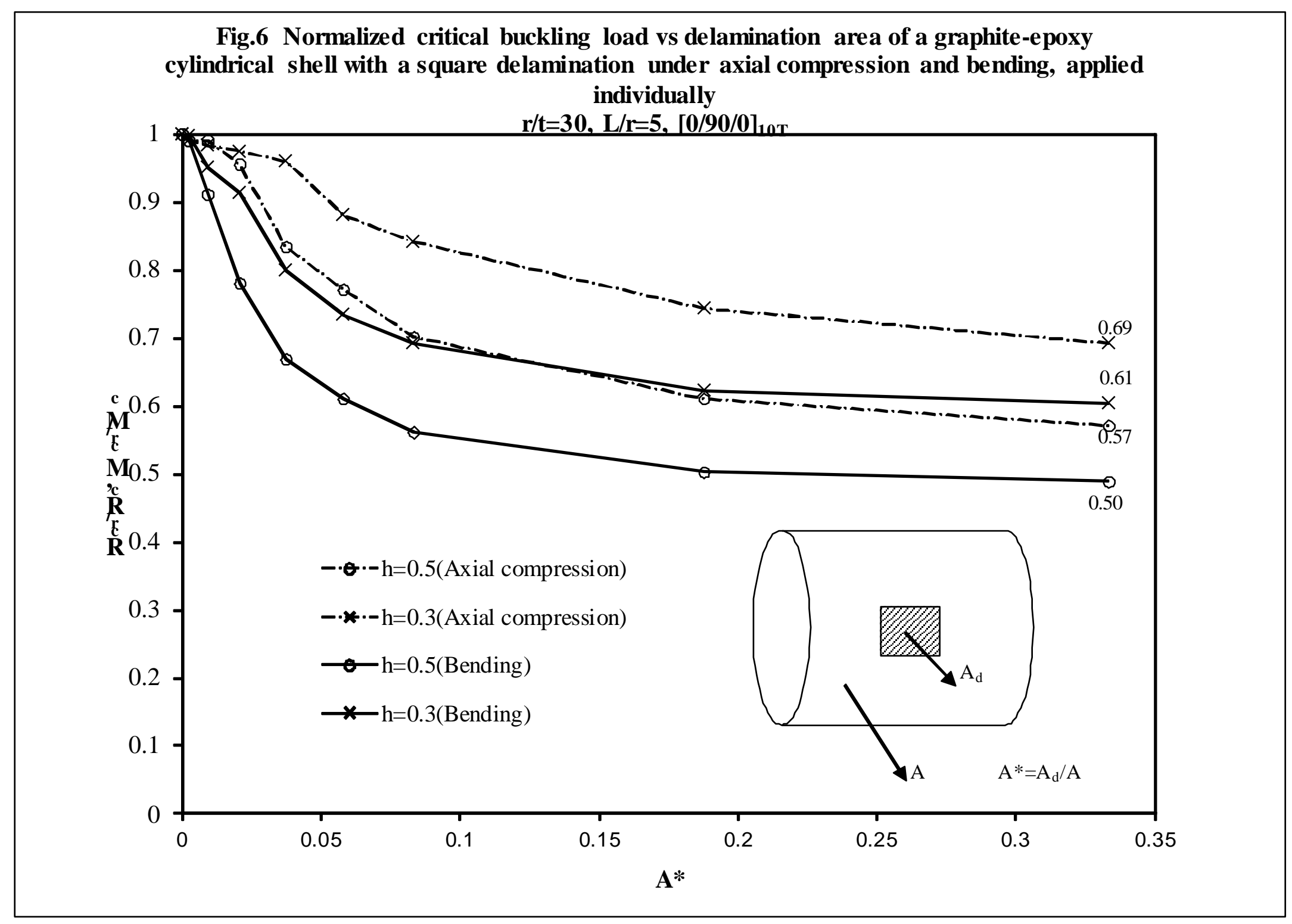




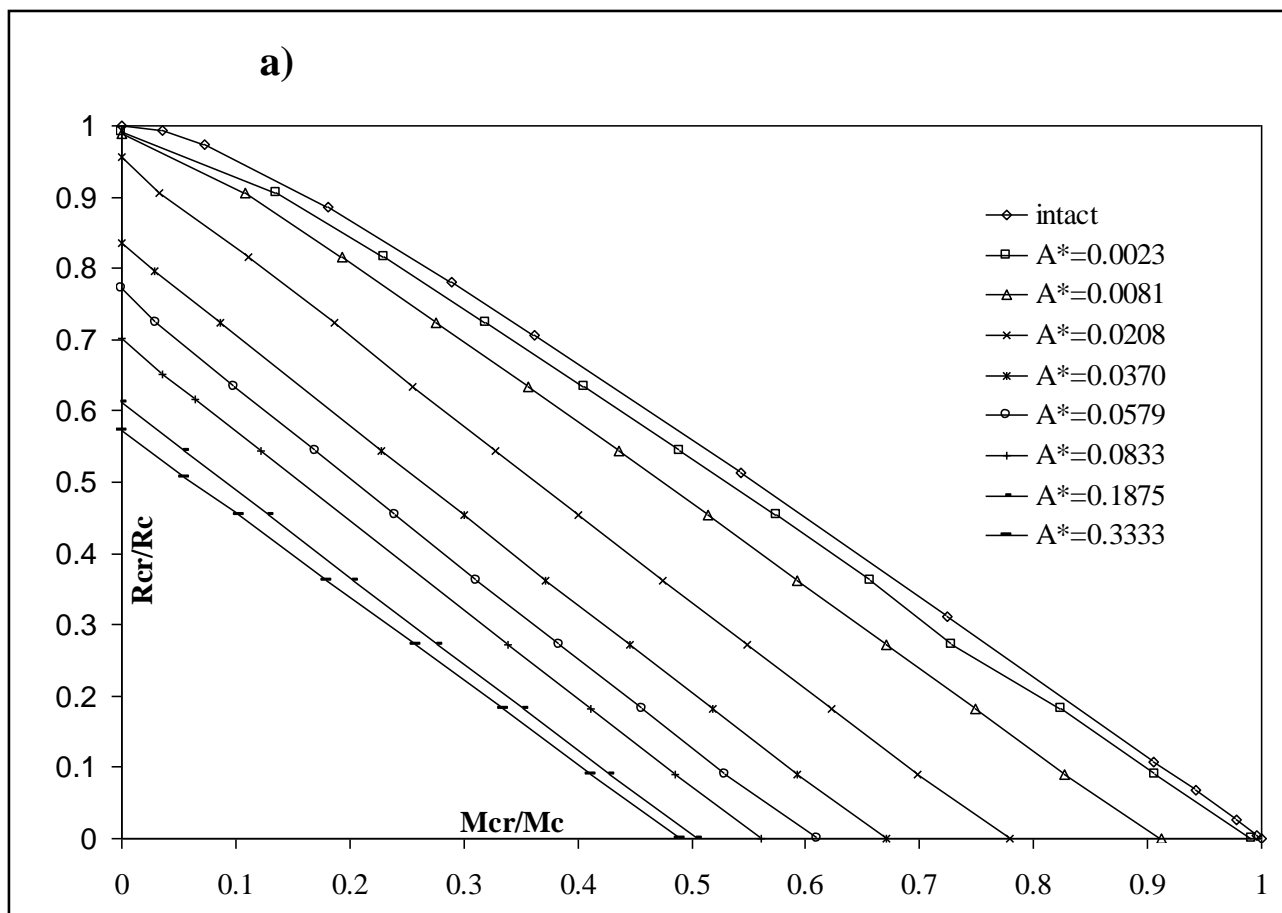

\section{b)}

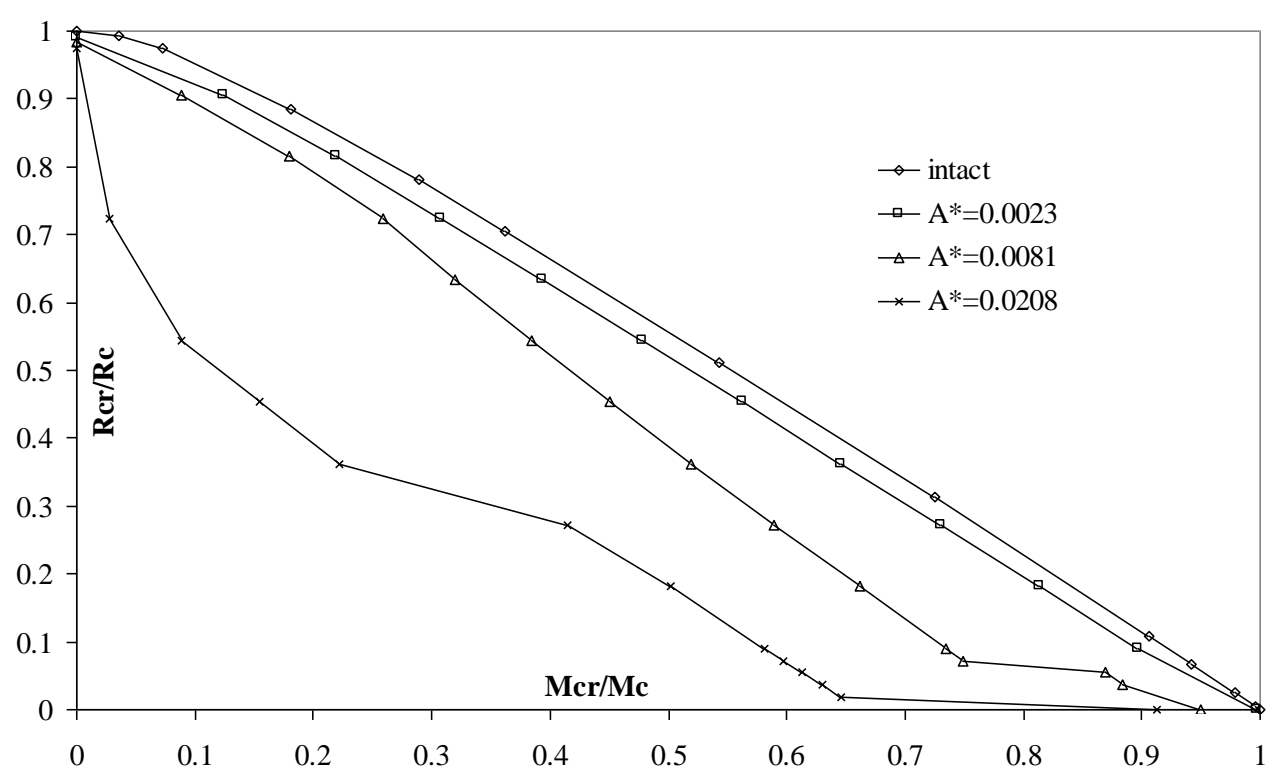

Fig. 7 Interaction buckling curve, axial compressive load vs bending, for a graphite-epoxy cylindrical shell having a square delamination with different delamination areas, $\left.\left.r / t=30, L / r=5,[0 / 90 / 0]_{10 T}, a\right) h=0.5 \quad b\right) h=0.3$ 
a)

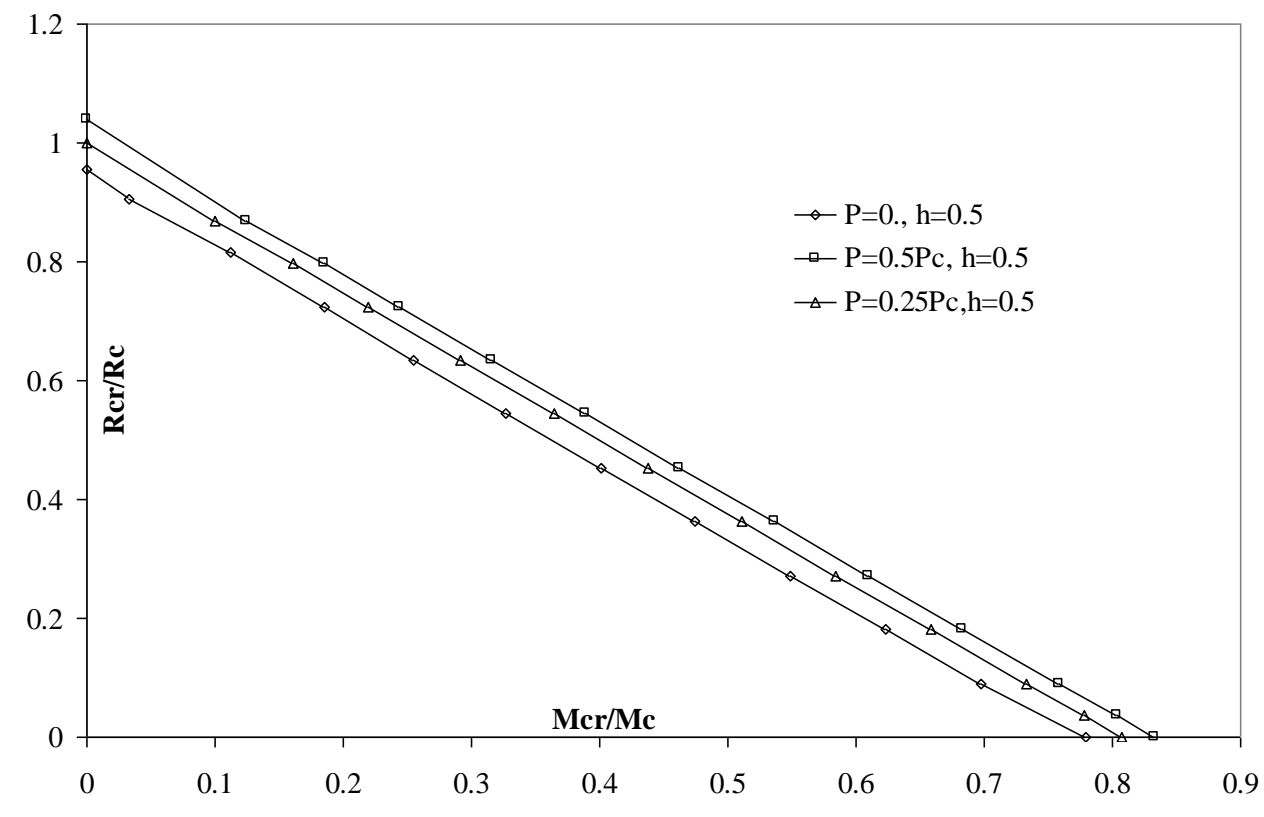

b)ireshi, A. Feb 2008 In : Composite Structures.82, 3, p. $422-43311$ p.

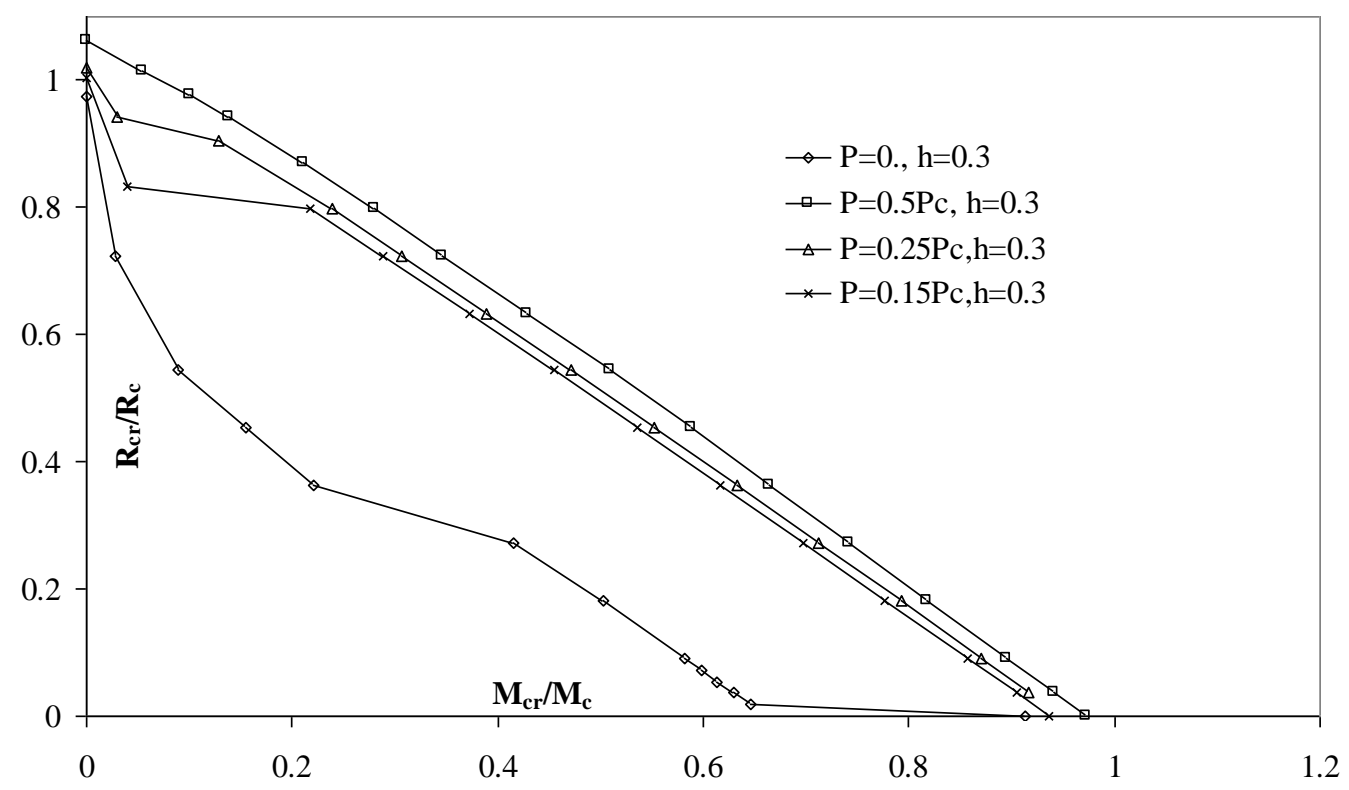

Fig. 8a-b Effect of internal pressure on the interaction buckling curve, axial compressive load vs bending of a composite cylinder with a square delamination $\left.\left.A^{*}=0.02, \mathrm{~L} / \mathrm{r}=5, \mathrm{r} / \mathrm{t}=30,[0 / 90 / 0]_{10 \mathrm{~T}} \mathrm{a}\right) \mathrm{h}=0.5, \mathrm{~b}\right) \mathrm{h}=0.3$
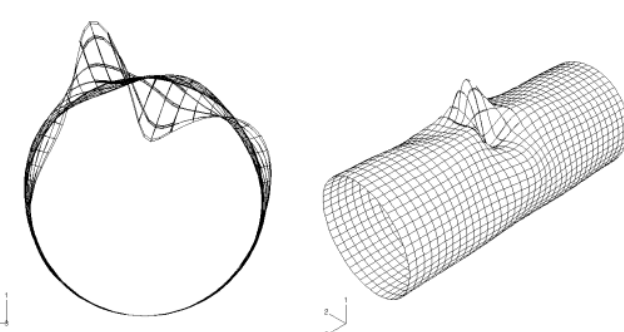

$\mathrm{R}=0.5 \mathrm{R}_{\mathrm{c}}, \mathrm{M}=0.36 \mathrm{M}_{\mathrm{c}}$

$\mathrm{P}=0 ., \mathrm{h}=0.5$

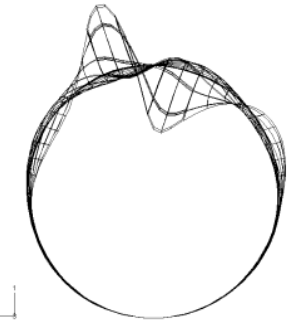

$\mathrm{R}=0.5 \mathrm{R}_{\mathrm{c}}, \mathrm{M}=0.39 \mathrm{M}_{\mathrm{c}}$

$\mathrm{P}=0.15 \mathrm{P}_{\mathrm{c}}, \mathrm{h}=0.5$
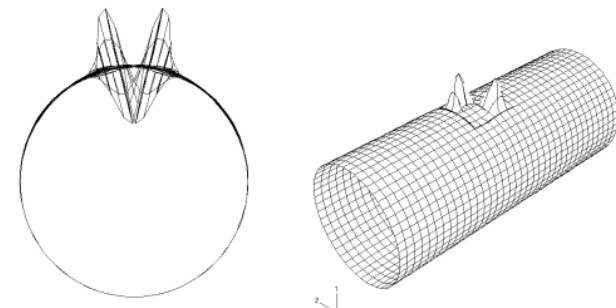

$\mathrm{R}=0.5 \mathrm{R}_{\mathrm{c}}, \mathrm{M}=0.2 \mathrm{M}_{\mathrm{c}}$

$\mathrm{P}=0 ., \mathrm{h}=0.3$

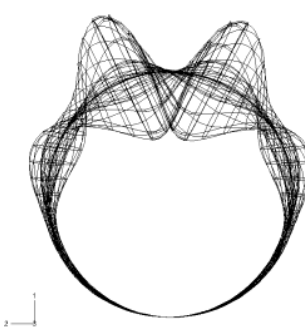

$\mathrm{R}=0.5 \mathrm{R}_{\mathrm{c}}, \mathrm{M}=0.49 \mathrm{M}_{\mathrm{c}}$ $\mathrm{P}=0.15 \mathrm{P}_{\mathrm{c}}, \mathrm{h}=0.3$

Fig. 8c Buckling mode shapes 
Fig.9a Axial compressive load vs end shortening of a graphite-epoxy cylindrical shell with different delamination length (extended along the entire circumference) with a preloading of $M=0.25 M c, L / r=5, r / t=30, h=0.5,[0 / 90 / 0]_{10}$

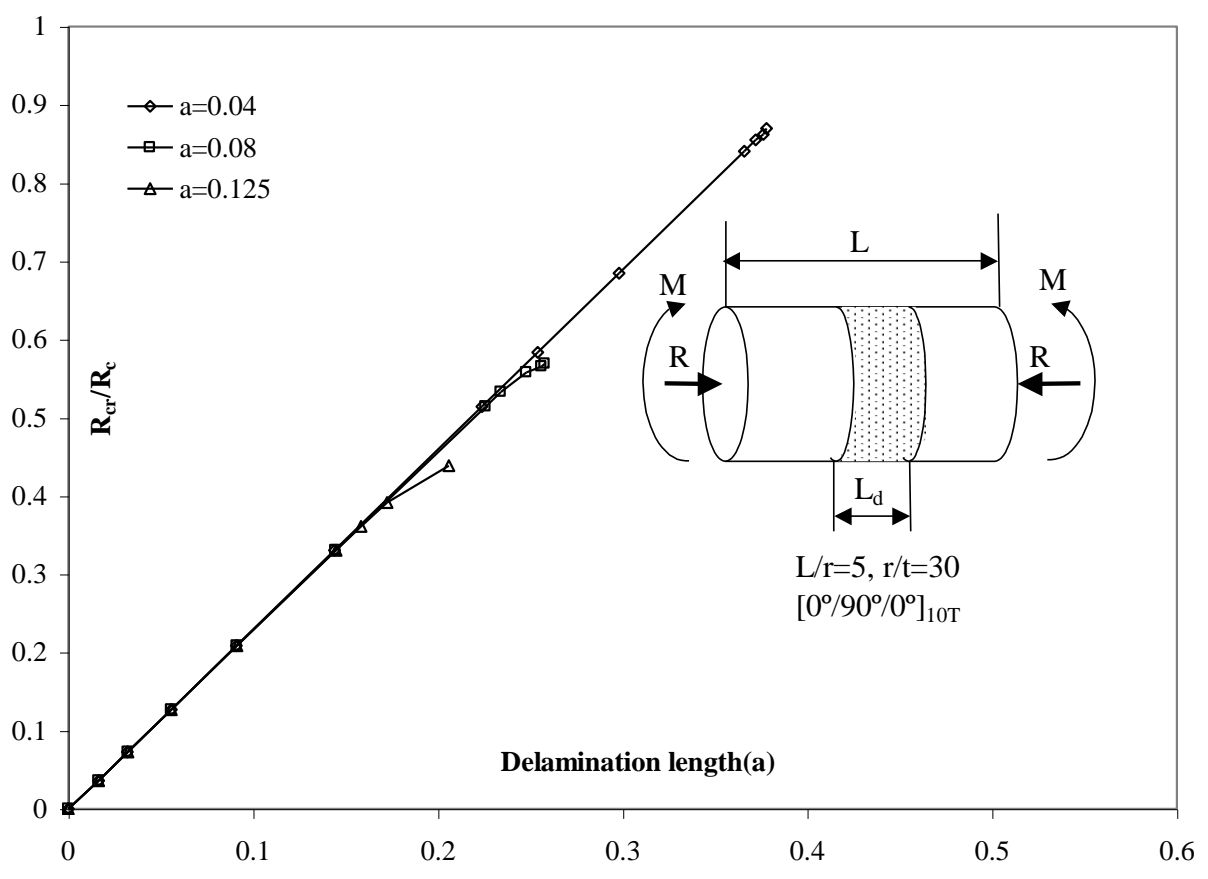

Fig.9b Axial compressive load vs end shortening of a graphite-epoxy cylindrical shell with the delamination length of $\mathbf{a}=\mathbf{0 . 1 2 5}$, extended along the entire circumference, with different values of preloading, $\mathrm{L} / \mathrm{r}=5, \mathrm{r} / \mathrm{t}=30, \mathrm{~h}=0.5,[0 / 90 / 0]_{10 \mathrm{~T}}$

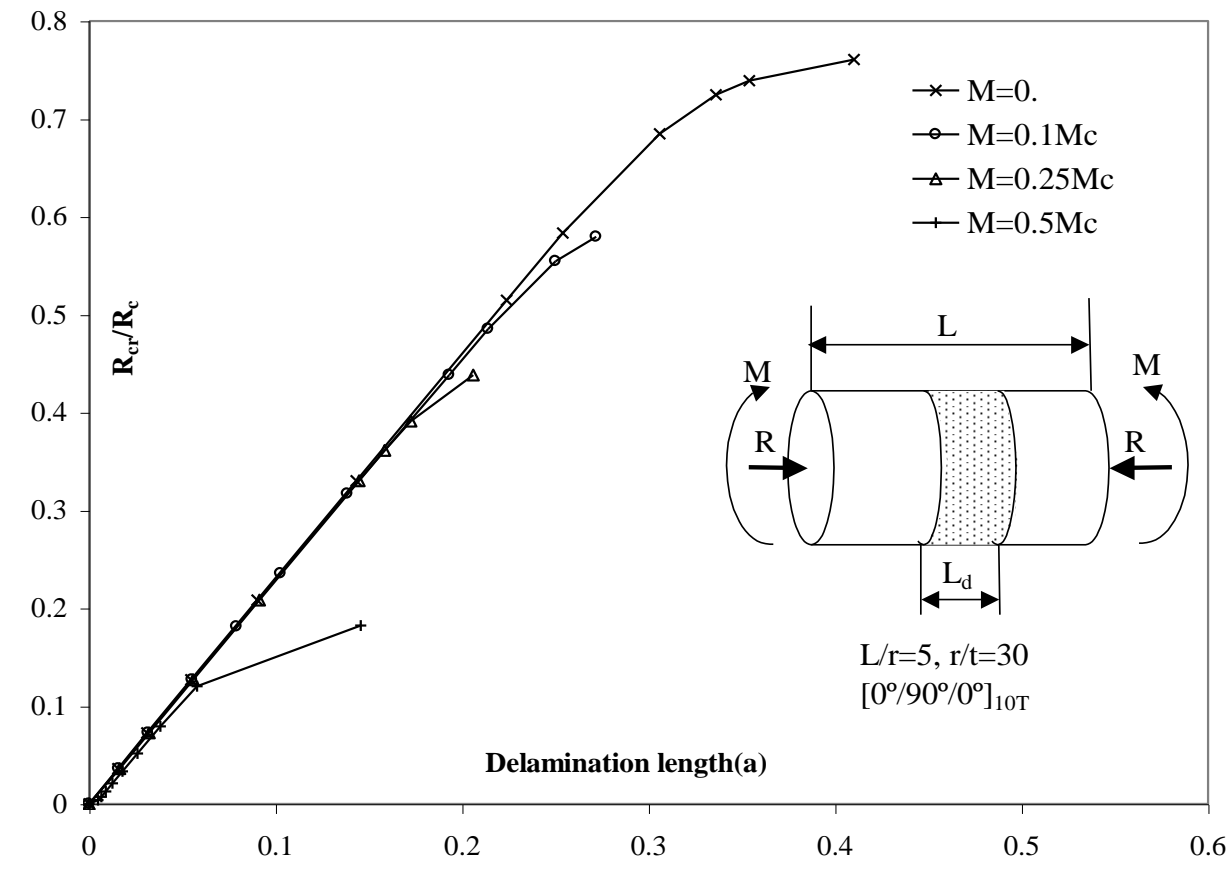




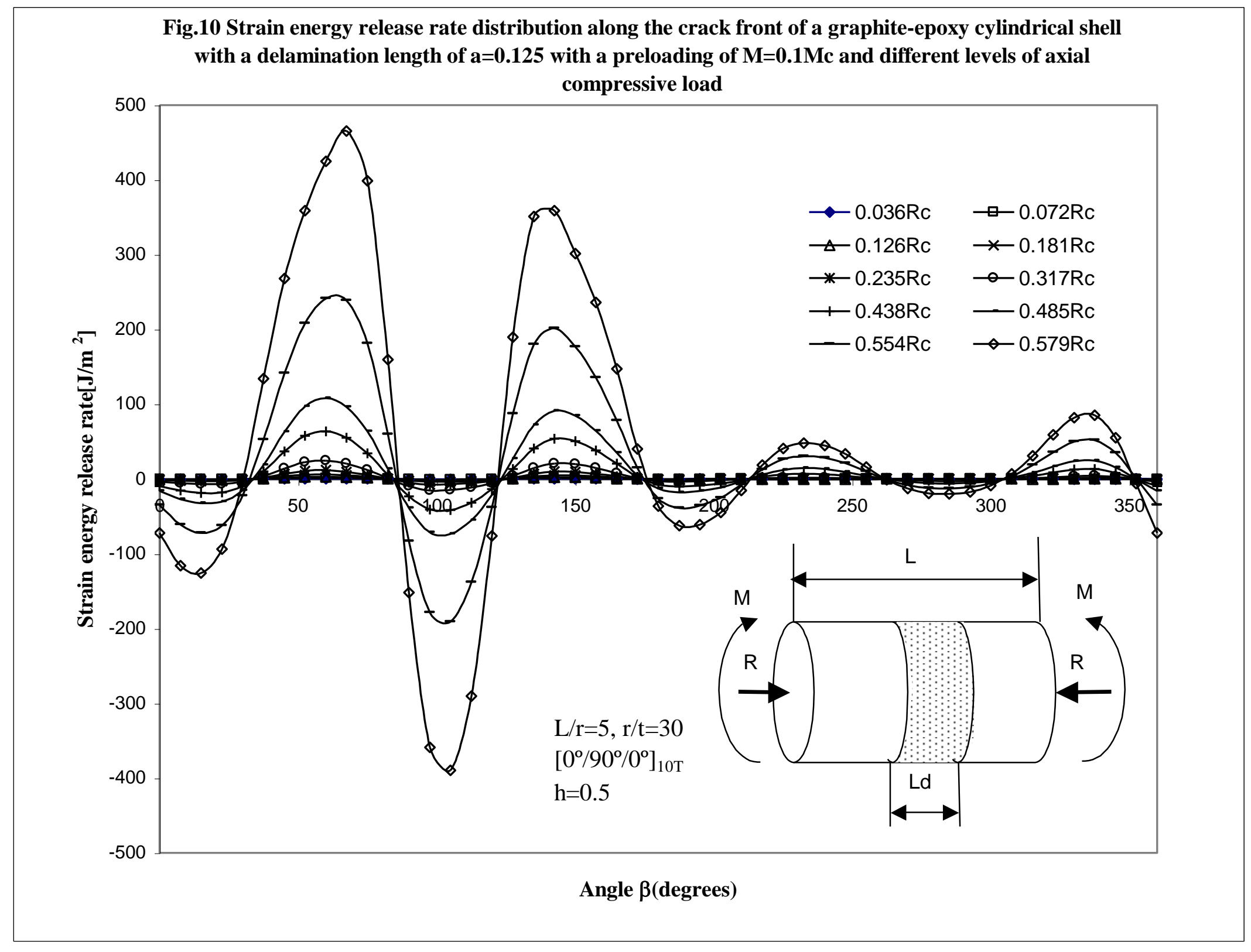


Tafreshi, A. Feb 2008 In : Composite Structures.82, 3, p. $422-43311$ p.

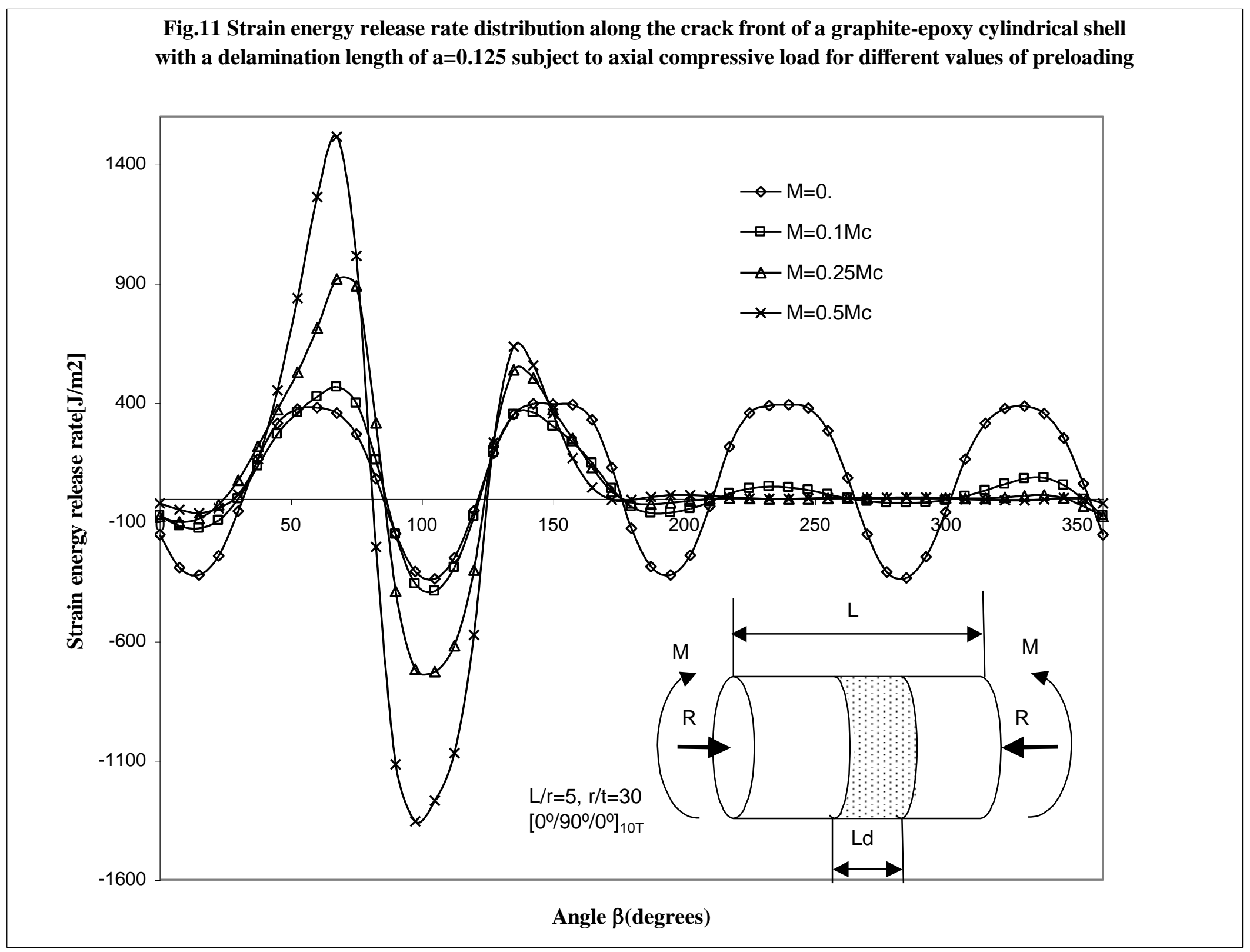

